\title{
Development of Japanese utility weights for the Adult Social Care Outcomes Toolkit (ASCOT) SCT4
}

\author{
Takeru Shiroiwa $^{1}$ (D) $\cdot$ Yoko Moriyama $^{2} \cdot$ Hiromi Nakamura-Thomas ${ }^{3} \cdot$ Mie Morikawa $^{4} \cdot$ Takashi Fukuda $^{1,2}$. \\ Laurie Batchelder $^{5}$ Eirini-Christina Saloniki ${ }^{5}$. Juliette Malley ${ }^{6}$
}

Accepted: 26 August 2019 / Published online: 4 September 2019

(c) The Author(s) 2019

\begin{abstract}
Purpose In developed countries, progressive rapid aging is increasing the need for social care. This study aimed to determine Japanese utility weights for the Adult Social Care Outcomes Toolkit (ASCOT) four-level self-completion questionnaire (SCT4).

Methods We recruited 1050 Japanese respondents from the general population, stratified by sex and age, from five major cities. In the best-worst scaling (BWS) phase, respondents ranked various social care-related quality of life (SCRQoL) states as "best," "worst," "second-best," or "second-worst," as per the ASCOT. Then, respondents were asked to evaluate eight different SCRQOL states by composite time-trade off (cTTO). A mixed logit model was used to analyze BWS data. The association between cTTO and latent BWS scores was used to estimate a scoring formula that would convert BWS scores to SC-QALY (social care quality-adjusted life year) scores.

Results Japanese BWS weightings for ASCOT-SCT4 were successfully estimated and found generally consistent with the UK utility weights. However, coefficients on level 3 of "Control over daily life" and "Occupation" domains differed markedly between Japan and the UK. The worst Japanese SCRQoL state was lower than that for the UK, as Japanese cTTO results showed more negative valuations. In general, Japanese SC-QALY score (for more than $90 \%$ of health states) was lower than that for the UK.

Conclusions We successfully obtained Japanese utility weights for ASCOT SCT4. This will contribute to the measurement and understanding of social care outcomes.
\end{abstract}

Keywords ASCOT $\cdot$ Preference $\cdot$ Best-worst scaling (BWS) $\cdot$ Time trade-off $($ TTO) $\cdot$ Quality of life $\cdot$ Social care $\cdot$ Social care-related quality of life (SCRQoL)

\section{Introduction}

Many developed countries are facing rapid population aging, with Japan being one of the world's fastest-aging countries. The proportion of elderly people (aged 65 and above) in 2016 was $27.3 \%$ in Japan [1], 23\% in Italy, and $21 \%$ in Germany, Portugal, and Finland [2]. Meanwhile, with a negative population growth rate, the proportion of elderly people in Japan is expected to increase even more in the next 50 years,

Electronic supplementary material The online version of this article (https://doi.org/10.1007/s11136-019-02287-6) contains supplementary material, which is available to authorized users.

Takeru Shiroiwa

t.shiroiwa@gmail.com

Extended author information available on the last page of the article reaching an estimated $38.4 \%$ in 2065 . In addition, a quarter of the entire population will be aged 75 years and above (these people are defined as "elderly in the latter stage of life" in Japan) [3]. The Japanese government updated its projected future social security costs in May 2018, and found that long-term care costs will increase to 2.5 times the 2018 costs by 2040 (from 1.9 to $3.3 \%$ of GDP). Thus, rapid aging will give rise to issues pertaining to financial and social sustainability in Japan. This situation is not limited to Japan; given the speed of population aging, other countries, including Asian countries such as China, South Korea, and Thailand, will face similar issues in the future.

In Japan, outcomes of long-term care are often evaluated based on activities of daily living (ADLs) including the Barthel Index [4] or instrumental activities of daily living (IADLs), which are measured by experts, not care service 
users. However, user-reported quality of life (QoL), an important maintenance or improvement goal for social care programs, is rarely assessed. While many measures have been developed for health-related QoL (HRQoL) [5-9], no standardized measure for measuring QoL of care service users currently exists. Recently, a research group at the University of Kent, in the United Kingdom, developed the Adult Social Care Outcomes Toolkit (ASCOT) [10-12], which is designed to measure social care-related QoL (SCRQoL). We developed a Japanese version of the ASCOT four-level selfcompletion questionnaire (SCT4) in 2017, with subsequent linguistic validation [9]. The development of a Dutch version has also been reported [13].

The ASCOT is a preference-based measure; that is, responses from care users can be converted to QoL scores (we sometimes call ASCOT scores "SC-QALY" or "social care quality-adjusted life years" scores) based on multiattribute utility theory (MAUT) [14]. Based on qualityadjusted life year (QALY) calculations, obtained scores can be applied to economic evaluations pertaining to care programs. Economic evaluation of social care programs is not frequently performed in Japan, although it is important to evaluate the efficiency of long-term care programs under circumstances of rapidly increasing social care costs. Utility weights for ASCOT have been developed for the UK [10], but not for Japan. As utility weights might differ between countries due to differences in population characteristics and potential issues with questionnaire translation [15], it is important to develop utility weights tailored to each country, and compare them across countries to better understand differences in preferences for ASCOT states among countries or regions. To this end, we conducted a study to determine Japanese utility weights for ASCOT-SCT4.

\section{Methods}

\section{ASCOT-SCT4}

The Japanese version of the ASCOT-SCT4 was used in the study, with permission from and in collaboration with the developer of the original measure, the ASCOT team at the Personal Social Services Research Unit (PSSRU) at the University of Kent, and the copyright holder, the University of Kent. The Japanese version of ASCOT was completed using the following process. First, we translated the UK version of ASCOT SCT4 into Japanese and had it backtranslated it into English by a different translator. Then, based on discussion among the developer, the Japanese research team, and the translation company, we produced a pre-final version, which was used for cognitive debriefing through interviewing a small number of potential users of ASCOT. We confirmed the tool's linguistic validity and finalized the Japanese version after adjustment from a clinical perspective.

The ASCOT-SCT4 (the Japanese version is provided in Appendix 1 in Electronic Supplementary Material) consists of eight domains, covering the following aspects of SCRQoL: control over daily life, personal cleanliness and comfort, food and drink, personal safety, social participation and involvement, occupation, accommodation cleanliness and comfort, and dignity. Each domain is represented by one item, except the dignity domain, which has two items. All items have four response options. Description of each level depends on each item; however, generally, the following descriptions are used: "can do (or is) as I want to do (or be)," "can do adequately (or is adequate)," "cannot adequately do (or is not adequate)," "cannot do (or isn't) at all."

The first dignity item (the 8th item overall, "how the user feels about the fact that they need social care") is not used in the scoring of the ASCOT instrument [16]. During development of ASCOT, it was found that some respondents were using the 9th item ("how the user feels about the way they receive social care") to express that they did not like needing help with aspects of life. The 8th item thus has a role of not only allowing respondents to express unhappiness with needing help but also helping them to answer the 9th item in the way that the tool intended.

\section{Best-worst scaling and time trade-off}

We measured preferences among ASCOT states in the general population by best-worst scaling (BWS) and composite time trade-off (cTTO), as described by Netten et al. [10]. BWS $[17,18]$ has been increasingly used to construct utility weights [19, 20]. According to a systematic review [21], 62 BWS studies had been conducted in healthcare research as of April 2016. In the area of social care, preference patterns and utility weights based on BWS (explained in detail in the next paragraph) and discrete choice experiment (DCE) (in which respondents are asked to choose one profile combining each domain between two shown profiles) are reportedly similar [22]. However, in this case, a problem with DCE was that the number of domains was too large to compare two profiles. As cognitive burden seems higher for respondents to the 8-domain DCE than to BWS, it was less feasible for the pre-survey. In addition, BWS can obtain more preference information than DCE per task [17]. Therefore, we applied BWS to the ASCOT valuation survey.

In the BWS survey, respondents are asked to choose "best" and "worst" options among presented alternatives. That is, BWS methods are classified into the following three types: case 1 (object case), case 2 (profile case), and case 3 (multi-profile case) [18]. In this study, we used the case 2 method, showing a profile combining each ASCOT SCT4 domain (Fig. 1). This is because, on the one hand, 
(a) first choice from eight items (best)

(b) second choice from seven items (worst)

\begin{tabular}{|c|c|}
\hline - My home is as clean and comfortable as I want & - My home is as clean and comfortable as I want \\
\hline - I feel less than adequately safe & - I feel less than adequately safe \\
\hline - I get adequate food and drink at OK times & - I get adequate food and drink at OK times \\
\hline - I don't feel at all clean or presentable & - I don't feel at all clean or presentable \\
\hline - I have as much control over my daily life as I want & - I have as much control over my daily life as I want \\
\hline - I have little social contact with people and feel socially isolated & \begin{tabular}{|l} 
- I have little social contact with people and feel socially isolated \\
\end{tabular} \\
\hline $\begin{array}{l}\text { - The way I'm helped and treated does not affect the way I think or feel } \\
\text { about myself }\end{array}$ & $\begin{array}{l}\text { The way I'm helped and treated does not affect the way I think or feel } \\
\text { about myself }\end{array}$ \\
\hline - I do some of the things I value or enjoy with my time, but not enough & - I do some of the things I value or enjoy with my time, but not enough \\
\hline (c) third choice from six items (second best) & fourth choice from five items (second worst) \\
\hline - My home is as clean and comfortable as I want & - My home is as clean and comfortable as I want \\
\hline - I feel less than adequately safe & - I feel less than adequately safe \\
\hline - I get adequate food and drink at OK times & - I get adequate food and drink at OK times \\
\hline - I don't feel at all clean or presentable & - I don't feel at all clean or presentable \\
\hline - I have as much control over my daily life as I want & - I have as much control over my daily life as I want \\
\hline - I have little social contact with people and feel socially isolated & - I have little social contact with people and feel socially isolated \\
\hline $\begin{array}{l}\text { - The way I'm helped and treated does not affect the way I think or feel } \\
\text { about myself }\end{array}$ & $\begin{array}{l}\text { - The way I'm helped and treated does not affect the way I think or feel } \\
\text { about myself }\end{array}$ \\
\hline - I do some of the things I value or enjoy with my time, but not enough & - I do some of the things I value or enjoy with my time, but not enough \\
\hline
\end{tabular}

Fig. 1 Example of BWS profile

preference for each item needs to be evaluated, whole on the other hand it is too complicated for respondents to compare profiles with too many domains. Respondents were asked to put themselves into an imaginary state (which is described by the profile) of being in need of care services, and then to select the best, worst, second-best, and second-worst domains in a sequential manner. That is, they first rated eight domains as "best," and then the remaining seven, six, and five domains as "worst," "second-best," and "secondworst" respectively. Selected domains were grayed-out and the remaining domains were presented for the next choice.

The TTO method is used to measure health state preferences [23]. First, respondents are asked to imagine living with a particular health state (profiles combining eight ASCOT items in this survey) for a certain amount of time (e.g., 10 years) (life A). After that, respondents have to indicate the number of years living in full health (life B) at which the respondents feel indifferent between life A and life B. We selected TTO rather than standard gamble (SG) based on evidence about feasibility for respondents [24].

In this survey, respondents were asked to compare 10 years' life with presented SCRQoL state (combining each ASCOT-SCT4 domain) with $x$ years' life with full SCRQoL state. We ascertained indifference between " $x$ years' life in full SCRQoL state" and "10 years' life in the presented SCRQoL state," increasing or decreasing the number of years. In the case of cTTO, the "worse than-dead" SCRQoL state was evaluated differently from the "better than-dead" state. To evaluate the former, cTTO employs lead-time TTO [25-27], which limits the minimum TTO score to -1 . When respondents were asked about the period of life covered by a SCRQoL state, their responses were facilitated by a visual representation of the question (a bar graduated from 0 to 10 , on which the respondents marked a particular number of years).

In the BWS phase, four blocks consisting of eight SCRQoL profiles (e.g., "24313222” is a profile with second level of control, forth (worst) level of personal care, etc.) were randomly allocated to each respondent [10]; 32 profiles were selected from all $4^{8}$ profiles using a fractional-factorial design (details should be referred to Netten et al. [10]) In the cTTO phase, eight blocks consisting of eight SCRQoL profiles (total 64 actually possible SCRQoL profiles) were similarly allocated to each respondent.

\section{Subjects and survey process}

The computer-based survey was conducted in five representative, geographically dispersed major cities in Japan (Sapporo, Tokyo, Nagoya, Osaka, and Fukuoka) and targeted the general population. Respondents (aged 20 to 79) were recruited by a research company (Anterio, Inc.) based on non-random sampling of 1050 respondents throughout Japan (i.e., roughly 200 respondents at each location). The sample number was not based on any rigid statistical consideration, but referred to a UK survey (part of the Measuring Outcomes for Public Service Users (MOPSU) project) that carried out power analysis to determine sample size. Respondents were stratified by sex and age group, and interviews were performed using a computer- (tablet-) based, one-on-one setting over intervals of 30 to $60 \mathrm{~min}$ at each local survey center. 
First, self-assessment of the respondent's own SCRQoL using ASCOT occurred, followed by BWS questions. The respondent was asked to value eight SCRQoL profiles by BWS and then other eight by cTTO. The order of BWS and TTO was not randomized, and BWS was performed before TTO tasks. After the valuation process was completed, experience with social care and demographic data were collected from respondents. The order of domain descriptions for BWS SCRQoL profiles was randomized to avoid positioning effects. Response time was recorded for BWS and cTTO processes.

All responses were automatically collected as electronic data. The survey was conducted from February to March 2018. Prior to administering the survey, all investigators received training for approximately half a day at each location. To ensure quality and consistency among investigators, the number of investigators was limited to roughly five at each location.

This study was approved by the ethics committee of the National Institute of Public Health, to which the corresponding author belongs (NIPH-IBRA \#12176).

\section{Statistical analysis}

A panel mixed logit model [28] was used for the analysis of BWS data considering sequential choice by each respondent (model \#1). A mixed logit model can consider heterogeneity of coefficients by relaxing the assumption of independence of irrelevant alternatives (IIA), whereas the simple multinomial logit (MNL) model assumes that all the responses are independent. In BWS tasks, it might be more appropriate if each respondent's best and second-best and worst and second-worst choices are separately regarded as clusters than if all choices (including both the best and worst choices) are considered together for each respondent, because there may be heterogeneity between two best and worst choices each. We also developed a mixed logit model treating each respondent's best or worst choices as different clusters (model \#2). In addition, the simple MNL model was applied for sensitivity analysis (model \#3).

Both mixed logit models and the MNL model include 7 (domain level; domain 5 is reference term) $+3 \times 8$ (item level; level 4 is reference term $)=31$ parameters to be estimated based on the collected data. Therefore, when choices are analyzed based on random utility theory, $U_{\mathrm{ij}}$ (the utility respondent $\mathrm{j}$ derives from choosing item $i$ ) is divided into an explainable component $\left(V_{i j}\right)$ and a random component $\left(\varepsilon_{i j}\right)$.

$U_{i j}=V_{i j}+\varepsilon_{i j}$

$V_{i j}=\beta_{1} X_{1}+\beta_{2} X_{2}+\cdots+\beta_{8} X_{8}+\beta_{11} X_{11}+\beta_{12} X_{12}+\cdots+\beta_{83} X_{83}$,

where $\beta_{p}$ is common effects of the $p$ th ASCOT domain ( $p=1$ accommodation, 2 safety, 3 food, 4 cleanliness, 6 participation, 7 dignity, 8 occupation) and $\beta_{p q}$ is effects of the $q$ th $(1 \leq q \leq 3)$ level of the $p$ th domain compared with the fourth level of the same domain. In the mixed logit model, let $\beta_{p}^{\mathrm{m}}$ and $\beta_{p}^{\mathrm{s}}$ be mean and scale parameters, respectively, for the random coefficient $\beta_{p}$,

$\beta_{p}=\beta_{p}^{\mathrm{m}}+\beta_{p}^{\mathrm{s}} \cdot \eta$,

where $\eta$ is a stochastic compartment with normal distribution. We also performed using a log-normal distribution as model \#4.

Although the number of items including a profile sequentially decreases from eight to five, data of four choices can be obtained from each respondent, i.e., we reflected the following situation in the coding: the best choice from among eight items, the worst choice from among seven items, the second best choice from among six items, and the second worst choice from among five items [10]. In case of the worst and second-worst choices, - 1 was used as $X_{p}$ and $X_{p q}$ if applicable [29]. Parameters in the utility function were estimated with Mixedlogit in STATA 15 using all the pooled choice data (best/worst and first/second). Respondents with a total BWS time of $<4.5 \mathrm{~min}$, which was considered too short based on the pre-test results of a valuation survey in the UK, were excluded under the assumption that normal respondents could not complete eight BWS tasks (4 choices were needed per BWS task) within that time.

Next, we calculated coefficients of all $4 \times 8=32$ items. The coefficients of each item can be calculated by sum of domain and level effects. For example, in the case of level 2 in "personal cleanliness and comfort" (domain 2), coefficients are computed by the sum of coefficients of "domain 2 " $\left(\beta_{2}\right)$ and "level 2 in domain $2 "\left(\beta_{22}\right)$. After that, coefficients of 32 items were rescaled to be first level of "Control over daily life" domain $=1$ and fourth level of the same domain $=0$, by linear transformation, which is similar to the method used for the UK. We call these transformed coefficients weights. Finally, we calculated latent BWS scores of cTTO 64 states using the sum of each domain's applicable eight weights. Note that these latent BWS scores are not yet standardized to QoL scale ( $1=$ full health and $0=$ death); we need to convert them using cTTO data.

With regard to cTTO data, when respondents equated 10 years of life with better-than-dead SCRQoL state to $x$ years of life with perfect health, the QoL score was calculated as $x / 10$. Conversely, when $y$ years of life with perfect SCRQoL was equated with "life with perfect SCRQoL for 10 years, followed by life with worse-than-dead SCRQoL state for 10 years," then the QOL score was calculated as $y / 10$ - 1. Mean QOL scores of 64 SCRQoL states were calculated; as in the BWS phase, respondents with a total cTTO time of $<5.0$ min were excluded based on the pre-test results of a UK valuation survey. 
Last, to convert the latent BWS scores to QOL scores (or SC-QALY scores), the linear relation function $f(\bullet)$ between latent BWS scores and cTTO scores of 64 SCRQoL states was estimated; namely, $\mathrm{TTO}_{i}=f\left(\mathrm{BWS}_{i}\right)+\varepsilon_{i}$, where $\mathrm{TTO}_{i}$ is the observed mean cTTO score, and $\mathrm{BWS}_{i}$ is the latent BWS score for the $i$ th SCRQoL state $(1 \leq i \leq 64)$. However, the linear function, $f(x)=a x+b$, has a restriction that the maximum ([11111111]) latent BWS score is converted to 1 (which is the definition of the maximum SC-QALY score).

\section{Results}

The final sample included 1050 respondents adjusted for sex and age from five cities in Japan. Mean and median total response times to all the questions including BWS and TTO were $43.7 \mathrm{~min}$ (SD: 12.1) and $42 \mathrm{~min}$ (IQR 35-51 $\mathrm{min}$ ), respectively; $83.6 \%$ of respondents completed all questions in 30 to $60 \mathrm{~min}$.

Mean and median response times for all the BWS procedures were $10.6 \mathrm{~min}$ (SD: 4.7) and $9.6 \mathrm{~min}$ (IQR 7.3-12.7 min), respectively. Thirty-two (3.0\%) respondents with total BWS times of $<4.5$ min were excluded from the statistical analysis set. On the other hand, mean and median response times for the cTTO procedure were $10.7 \mathrm{~min}$ (SD: 44) and 10.1 min (IQR 7.6-13.3 min), respectively. Fiftynine (5.6\%) respondents with a total cTTO time of $<5.0 \mathrm{~min}$ were excluded from the statistical analysis set.

\section{Demographic factors}

The background of the respondents was comparable with that of the general population. Table 1 summarizes respondent demographic factors. Household income of $49.3 \%$ of respondents was less than JPY 6 million (USD 55,000; USD $1=$ JPY 110 as of July 2018) compared to a median household income of all Japanese families of JPY 5.4 million (USD 49,000) in 2016 [30]. The proportion of permanent full time workers was $39.8 \%$, which is roughly comparable with $33.6 \%$ in the Japanese population, calculated by the "number of permanent full time workers/number of people aged 15 or over" according to government statistics in 2016 $[31,32]$. The proportion of homemakers was $18.2 \%$, which is similar with $13.5 \%$ in the Japanese population calculated by the "number of homemakers/number of people aged 15 or over" in 2016. Regarding education level, $43.6 \%$ of respondents had college, university, or graduate education, suggesting that approximately half of our respondents had received more than 14 years' education (if vocational schools are also included, the rate is more than 50\%). According to national statistics [33], the "number of people with college, university, or graduate education/number of people aged 20 years or over" in 2012 was $19.8 \%$. Finally, $60.6 \%$ of our
Table 1 Demographic characteristics of survey respondents

\begin{tabular}{|c|c|c|}
\hline & Number & Percentage \\
\hline \multicolumn{3}{|l|}{ Sex } \\
\hline Male & 525 & 50.0 \\
\hline Female & 525 & 50.0 \\
\hline \multicolumn{3}{|l|}{ Age } \\
\hline $20-29$ & 174 & 16.6 \\
\hline $30-39$ & 176 & 16.8 \\
\hline $40-49$ & 175 & 16.7 \\
\hline $50-59$ & 175 & 16.7 \\
\hline $60-69$ & 175 & 16.7 \\
\hline $70-79$ & 175 & 16.7 \\
\hline \multicolumn{3}{|l|}{ Region } \\
\hline Tokyo & 208 & 19.8 \\
\hline Sapporo & 210 & 20.0 \\
\hline Fukuoka & 211 & 20.1 \\
\hline Osaka & 211 & 20.1 \\
\hline Nagoya & 210 & 20.0 \\
\hline \multicolumn{3}{|l|}{ Employment } \\
\hline Full-time worker (permanent) & 397 & 37.8 \\
\hline Full-time worker (non-permanent) & 53 & 5.0 \\
\hline Part-time worker & 198 & 18.9 \\
\hline Self-employed or manager & 63 & 6.0 \\
\hline Housemaker & 191 & 18.2 \\
\hline Retired & 95 & 9.0 \\
\hline Student & 48 & 4.6 \\
\hline Other & 5 & 0.5 \\
\hline \multicolumn{3}{|l|}{ Household income (JPY 10,000) } \\
\hline$<100$ & 25 & 2.4 \\
\hline $100-200$ & 48 & 4.6 \\
\hline $200-400$ & 210 & 20.0 \\
\hline $400-600$ & 234 & 22.3 \\
\hline $600-1000$ & 284 & 27.0 \\
\hline $1000-1500$ & 73 & 7.0 \\
\hline $1500-2000$ & 11 & 1.0 \\
\hline$>2000$ & 6 & 0.6 \\
\hline No answer & 159 & 15.1 \\
\hline \multicolumn{3}{|l|}{ Education } \\
\hline Elementary or junior high school & 35 & 3.3 \\
\hline High school & 418 & 39.8 \\
\hline Vocational school & 138 & 13.1 \\
\hline College & 118 & 11.2 \\
\hline University & 329 & 31.3 \\
\hline Graduate school & 12 & 1.1 \\
\hline \multicolumn{3}{|l|}{ Marital status } \\
\hline Unmarried & 278 & 26.5 \\
\hline Married & 636 & 60.6 \\
\hline Divorced/widowed & 136 & 13.0 \\
\hline
\end{tabular}


respondents were married, which is similar to $60.3 \%$ calculated by the "number of married people/number of people aged 20 or over" in 2015.

\section{BWS results}

Table 2 shows the estimated coefficients of the BWS analysis in the both mixed logit model and MNL, in which the 4th (worst) level of "control over daily life" was used as the reference. Table 3 shows standardized Japanese BWS weightings generated from a linear transformation of estimated coefficients shown in Table 2; coefficients of levels 1 and 4 in "control over daily life" domain are 1 and 0 , respectively. Table 3 derives from the coefficients from model \#3 in Table 2, because the log likelihood of this model is the best and coefficients were not very different among the four models. The most preferred item was level 1 in the "occupation" domain, and the second-most preferred was level 1 in the same "control over daily life." In UK, the most preferred item was level 1 in the "control over daily life" domain. In Japan, the least preferred item was level 4 in the "control over daily life" and "dignity" domains; the former item is the least preferred, similarly to the UK. All the coefficients in Table 2 were consistent; weights at the higher level in the same domain are higher, and that at the lower level, lower.

\section{cTTO results and conversion to SC-QALY scores}

Mean and median response times for the cTTO procedure were $10.7 \mathrm{~min}$ (SD: 44) and 10.1 $\mathrm{min}$ (IQR 7.6-13.3 min), respectively. Fifty-nine (5.6\%) respondents with a total cTTO time of $<5.0$ min were excluded from the statistical analysis. The worst TTO score was - 0.327 [44444444], and the best score was 0.746 [11121212]. Median of 64 TTO scores was 0.240 . Twenty health states (31\%) were evaluated as WTD; scores were less than 0. Figure 2 shows the relationships between latent BWS scores (calculated using Table 3) and cTTO scores of 64 states. Based on the linear relationship between latent BWS score and cTTO score, latent BWS scores can be converted to SC-QALY scores using the following formula:

$$
\begin{aligned}
& \text { SC-QALY score }=(0.221 \times \text { latentBWS scorecalculatedusing Table } 3) \\
& -0.496 . ; \text { Slope: } \quad 0.221(t=55.6, p ; 0.001), \\
& \text { intercept: } \quad-0.496(t=-18.4, p ; 0.001), \quad R^{2}=0.91
\end{aligned}
$$

SC-QALY scores were distributed between maximum and minimum SC-QALY scores of 1.00 and -0.38 , respectively. Finally, we compared Japanese SC-QALY scores with UK scores for all $4^{8}=65,536$ patterns. Figure 3 shows a scatter plot of Japanese and UK scores; compared to Japanese SCQALY scores, $91.0 \%$ of UK SC-QALY scores $(N=59,666)$ were higher. Pearson correlation coefficient and intraclass correlation coefficients (ICCs) were respectively 0.91 and 0.70 between Japanese and UK SC-QALY score. The calculation methods of ASCOT scores are illustrated in the "Appendix".

\section{Discussion}

In this study, we successfully determined Japanese utility weights for ASCOT SCT4 through a survey of 1050 participants who responded to both BWS and cTTO questions. These utility weights reflect Japanese preferences and can be used to calculate SC-QALY scores for economic evaluation. This means SCRQOL scores measured by ASCOT SCT4 can meet the requirements of Japanese official guidelines for the economic evaluation of drugs/medical devices ("the use of an instrument with a scoring algorithm developed in Japan is recommended") [34].

The comparison of utility weights between Japan and the UK (Table 3) revealed consistency between Japanese and UK weightings. Pearson correlation coefficient was 0.91 and ICC was 0.70 between Japanese and UK scores. However, some coefficients greatly differed between Japan and the UK. For instance, the weight of level 3 in "control over daily life" and "occupation" domains greatly differed between Japan and the UK. This may reflect a Japanese preference called "pin pin korori," which involves a wish for two things: "The first is a long, spry life. The second is a quick and painless death" (The Economist). The finding that Japanese weights for lower levels in the "dignity" domain tended to be smaller than UK weights lends further support to this interpretation. Generally, the third level's weight in each domain (especially, occupation, accommodation, and dignity, in addition to control) was smaller in Japan than in the UK.

Conversion formulae for SC-QALY score, "SC-QALY score $=(0.221 \times$ latent BWS score $)-0.496$ " in Japan and "SC-QALY score $=(0.203 \times$ latent BWS score $)-0.466$ " in the UK, were also comparable. A comparison of SC-QALY scores revealed generally lower scores for Japanese compared to the UK. These lower Japanese SC-QALY scores are likely due to the lower Japanese cTTO scores for 64 SCRQOL states compared to those of the UK. This tendency has not been observed with some other preference-based measures; for instance, according to a EQ-5D-5L valuation study, the minimum score on EQ-5D (55555) was - 0.025 in Japan [35] and - 0.285 in the UK [36]. In the case of EQ$5 \mathrm{D}-5 \mathrm{~L}$, people in the UK have more negative valuations of worse health states by TTO. We cannot explain for certain why these differences arose; one possible reason is that in a Japanese ASCOT preference study, cTTO scores (normal TTO for positive score and lead time TTO for negative score) were used, whereas in the UK, normal TTO was also used for the worse-than-dead state. Minimum cTTO score 
Table 2 Estimated coefficients from BWS responses

\begin{tabular}{|c|c|c|c|c|c|c|c|c|}
\hline \multirow{5}{*}{$\begin{array}{l}\text { Statistical model } \\
\text { Cluster } \\
\text { Distribution } \\
\text { Parameter }\end{array}$} & \multirow{2}{*}{\multicolumn{2}{|c|}{$\frac{\text { Model \#1 }}{\text { Multinomial logit }}$}} & \multirow{2}{*}{\multicolumn{2}{|c|}{$\frac{\text { Model \#2 }}{\text { Mixed logit }}$}} & \multicolumn{2}{|l|}{ Model \#3 } & \multicolumn{2}{|l|}{ Model \#4 } \\
\hline & & & & & & & & \\
\hline & \multicolumn{2}{|l|}{-} & \multicolumn{2}{|c|}{ Respondents } & \multicolumn{4}{|c|}{ Respondents and choices } \\
\hline & \multicolumn{2}{|l|}{-} & \multicolumn{4}{|l|}{ Normal } & \multicolumn{2}{|c|}{ Log normal } \\
\hline & Estimate & SE & Estimate & SE & Estimate & SE & Estimate & SE \\
\hline \multicolumn{9}{|l|}{ Domain level } \\
\hline Accommodation & 0.1958 & 0.0485 & 0.2033 & 0.0492 & 0.2124 & 0.0572 & -0.4197 & 0.0736 \\
\hline Safety & 0.2806 & 0.0496 & 0.2953 & 0.0533 & 0.3620 & 0.0585 & -0.3074 & 0.0699 \\
\hline Food & 0.2492 & 0.0507 & 0.2845 & 0.0531 & 0.3487 & 0.0602 & -0.2085 & 0.0650 \\
\hline Cleanliness & 0.4998 & 0.0500 & 0.5084 & 0.0508 & 0.5743 & 0.0566 & -0.0212 & 0.0640 \\
\hline Control & Ref. & & Ref. & & Ref. & & Ref. & \\
\hline Participation & 0.1103 & 0.0491 & 0.1136 & 0.0501 & 0.1330 & 0.0553 & -0.4405 & 0.0750 \\
\hline Dignity & 0.0954 & 0.0490 & 0.0914 & 0.0513 & 0.0005 & 0.0576 & -0.7710 & 0.1043 \\
\hline Occupation & 0.3716 & 0.0509 & 0.4034 & 0.0529 & 0.5452 & 0.0582 & -0.0343 & 0.0534 \\
\hline \multicolumn{9}{|l|}{ Item level } \\
\hline \multicolumn{9}{|l|}{ Accommodation } \\
\hline Level 1 & 3.0961 & 0.0526 & 3.1756 & 0.0536 & 3.5226 & 0.0635 & 3.4131 & 0.0588 \\
\hline Level 2 & 2.7978 & 0.0531 & 2.8744 & 0.0540 & 3.1502 & 0.0634 & 3.0506 & 0.0595 \\
\hline Level 3 & 0.4620 & 0.0516 & 0.4708 & 0.0523 & 0.5459 & 0.0562 & 0.4031 & 0.0528 \\
\hline \multicolumn{9}{|l|}{ Safety } \\
\hline Level 1 & 2.3374 & 0.0550 & 2.3536 & 0.0559 & 2.5613 & 0.0625 & 2.4852 & 0.0608 \\
\hline Level 2 & 1.0467 & 0.0543 & 1.0846 & 0.0547 & 1.2074 & 0.0587 & 1.0892 & 0.0558 \\
\hline Level 3 & 0.2143 & 0.0522 & 0.2390 & 0.0531 & 0.2753 & 0.0569 & 0.1670 & 0.0532 \\
\hline \multicolumn{9}{|l|}{ Food } \\
\hline Level 1 & 3.0061 & 0.0541 & 3.0517 & 0.0552 & 3.2185 & 0.0645 & 3.0849 & 0.0607 \\
\hline Level 2 & 2.7677 & 0.0541 & 2.8139 & 0.0553 & 2.9394 & 0.0637 & 2.7967 & 0.0601 \\
\hline Level 3 & 0.5994 & 0.0532 & 0.6064 & 0.0540 & 0.6573 & 0.0572 & 0.4365 & 0.0536 \\
\hline \multicolumn{9}{|l|}{ Cleanliness } \\
\hline Level 1 & 2.1248 & 0.0544 & 2.1886 & 0.0554 & 2.4154 & 0.0617 & 2.3738 & 0.0645 \\
\hline Level 2 & 1.9829 & 0.0553 & 2.0474 & 0.0563 & 2.2212 & 0.0623 & 2.1896 & 0.0652 \\
\hline Level 3 & 0.3392 & 0.0522 & 0.3483 & 0.0531 & 0.3894 & 0.0567 & 0.3370 & 0.0566 \\
\hline \multicolumn{9}{|l|}{ Control } \\
\hline Level 1 & 3.6181 & 0.0534 & 3.7034 & 0.0543 & 4.0760 & 0.0586 & 4.6150 & 0.0541 \\
\hline Level 2 & 3.4475 & 0.0533 & 3.5336 & 0.0543 & 3.8895 & 0.0584 & 4.4245 & 0.0538 \\
\hline Level 3 & 0.3035 & 0.0512 & 0.3147 & 0.0519 & 0.3610 & 0.0545 & 0.9886 & 0.0467 \\
\hline \multicolumn{9}{|l|}{ Participation } \\
\hline Level 1 & 2.8462 & 0.0537 & 2.9209 & 0.0546 & 3.1844 & 0.0615 & 3.0673 & 0.0589 \\
\hline Level 2 & 2.6323 & 0.0542 & 2.6982 & 0.0552 & 2.9607 & 0.0618 & 2.8377 & 0.0594 \\
\hline Level 3 & 1.1141 & 0.0537 & 1.1488 & 0.0545 & 1.2745 & 0.0579 & 1.1450 & 0.0556 \\
\hline \multicolumn{9}{|l|}{ Dignity } \\
\hline Level 1 & 2.4354 & 0.0547 & 2.4768 & 0.0556 & 2.8675 & 0.0643 & 2.7330 & 0.0600 \\
\hline Level 2 & 1.1543 & 0.0533 & 1.1910 & 0.0541 & 1.4144 & 0.0592 & 1.2564 & 0.0557 \\
\hline Level 3 & 0.1962 & 0.0509 & 0.1998 & 0.0519 & 0.2387 & 0.0566 & 0.1264 & 0.0537 \\
\hline \multicolumn{9}{|l|}{ Occupation } \\
\hline Level 1 & 3.3469 & 0.0543 & 3.4176 & 0.0555 & 3.6034 & 0.0641 & 3.5408 & 0.0614 \\
\hline Level 2 & 3.2118 & 0.0540 & 3.2695 & 0.0551 & 3.4306 & 0.0637 & 3.3692 & 0.0610 \\
\hline Level 3 & 0.3217 & 0.0531 & 0.3302 & 0.0540 & 0.3436 & 0.0564 & 0.2302 & 0.0543 \\
\hline Log likelihood & $-46,882$ & & $-46,489$ & & $-44,764$ & & $-45,043$ & \\
\hline
\end{tabular}

$P$ value of all the coefficients are less than 0.001

$S E$ standard error 
Table 3 Comparison of Japanese and UK BWS weightings

\begin{tabular}{|c|c|c|c|}
\hline Item & Level & Japanese weight & UK weight \\
\hline \multirow[t]{4}{*}{ Control over daily life } & 1 & 1 & 1 \\
\hline & 2 & 0.954 & 0.919 \\
\hline & 3 & 0.089 & 0.541 \\
\hline & 4 & 0 & 0 \\
\hline \multirow[t]{4}{*}{ Personal cleanliness and comfort } & 1 & 0.734 & 0.911 \\
\hline & 2 & 0.686 & 0.789 \\
\hline & 3 & 0.236 & 0.265 \\
\hline & 4 & 0.141 & 0.195 \\
\hline \multirow[t]{4}{*}{ Food and drink } & 1 & 0.875 & 0.879 \\
\hline & 2 & 0.807 & 0.775 \\
\hline & 3 & 0.247 & 0.294 \\
\hline & 4 & 0.086 & 0.184 \\
\hline \multirow[t]{4}{*}{ Personal safety } & 1 & 0.717 & 0.880 \\
\hline & 2 & 0.385 & 0.452 \\
\hline & 3 & 0.156 & 0.298 \\
\hline & 4 & 0.089 & 0.114 \\
\hline \multirow[t]{4}{*}{ Social participation and involvement } & 1 & 0.814 & 0.873 \\
\hline & 2 & 0.759 & 0.748 \\
\hline & 3 & 0.345 & 0.497 \\
\hline & 4 & 0.033 & 0.241 \\
\hline \multirow[t]{4}{*}{ Occupation } & 1 & 1.018 & 0.962 \\
\hline & 2 & 0.975 & 0.927 \\
\hline & 3 & 0.218 & 0.567 \\
\hline & 4 & 0.134 & 0.170 \\
\hline \multirow[t]{4}{*}{ Accommodation cleanliness and comfort } & 1 & 0.916 & 0.863 \\
\hline & 2 & 0.825 & 0.780 \\
\hline & 3 & 0.186 & 0.374 \\
\hline & 4 & 0.052 & 0.288 \\
\hline \multirow[t]{4}{*}{ Dignity } & 1 & 0.704 & 0.847 \\
\hline & 2 & 0.347 & 0.637 \\
\hline & 3 & 0.059 & 0.295 \\
\hline & 4 & 0.000 & 0.263 \\
\hline
\end{tabular}

is limited to -1 , though normal TTO score can be less than -1 . This methodological difference might have affected the results. Another interpretation is that Japanese preferences were truly lower than UK preferences in the area of social care, but not in healthcare. If this is true, the concept of "pin pin korori" might have influenced the cTTO scores among our respondents.

Regarding the limitations of this study, respondents were not recruited using a rigid random sampling method, because the time required for the survey was assumed to be too long to do so. We judged that a door-to-door survey (i.e., where investigators visit sampled people at their residence and ask them to respond to questions at the entrance or in a room) would be difficult to conduct. The sampling method we used is similar to that described for a preference survey of EQ-5D-5L [35]. Respondents mostly had characteristics similar to the general Japanese population, although, for instance, education level was higher in our sample. This may be regarded as another limitation of our analysis from the perspective of generalizability. Second, we applied mixed logit model clustered with each respondent's two best and two worst choices. This might imply that coefficients of the best and worst choices are heterogeneous. We assume that the absolute values of coefficients are not different between the best and worst choices; however, this may be another limitation of our analysis.

With the development of the Japanese ASCOT SCT4, it is now possible to calculate QALY for economic evaluation in the area of social care. However, some aspects of the Japanese ASCOT have not been clarified yet, because experiences with ASCOT use have not accumulated to a sufficient degree. For example, the relationship between ASCOT and other preference-based measures (e.g., EQ$5 \mathrm{D}-5 \mathrm{~L}$, which is the most frequently used measure for 
Fig. 2 Relationship between latent BWS and TTO scores

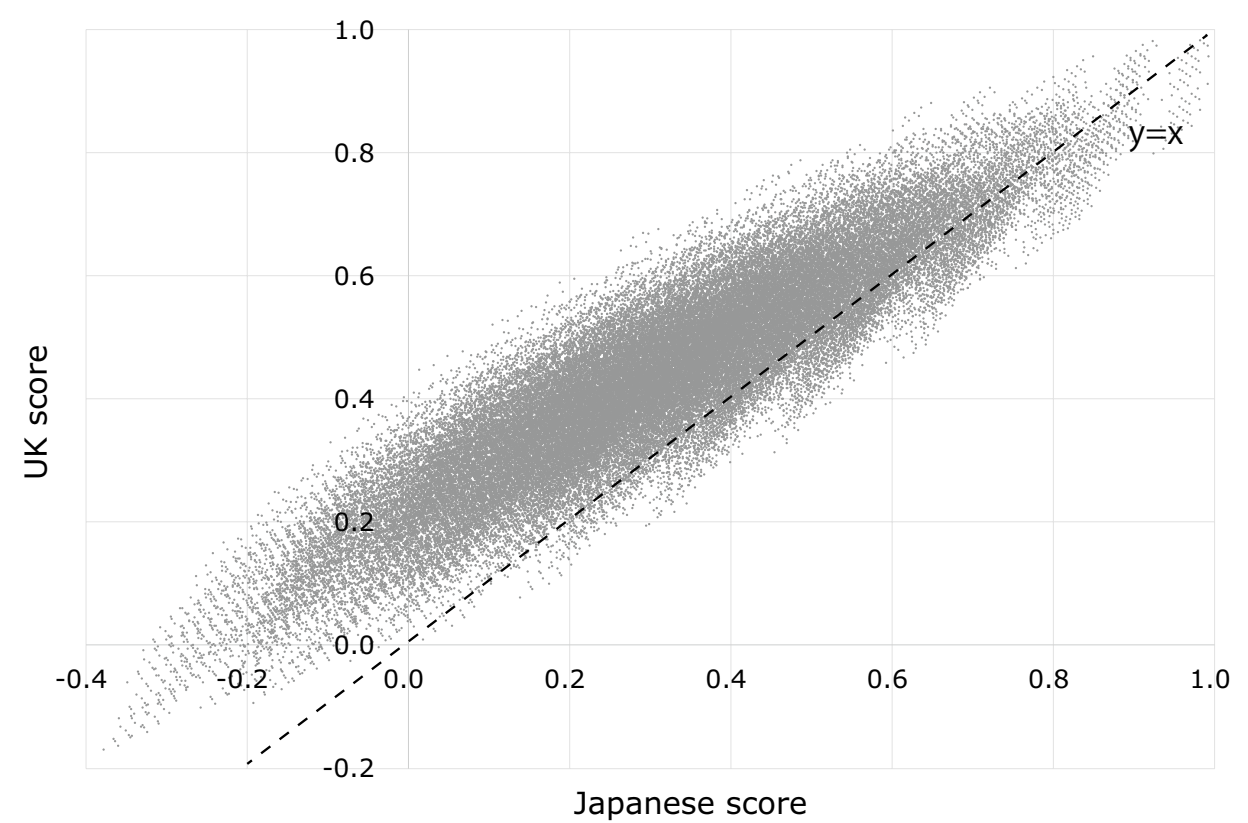

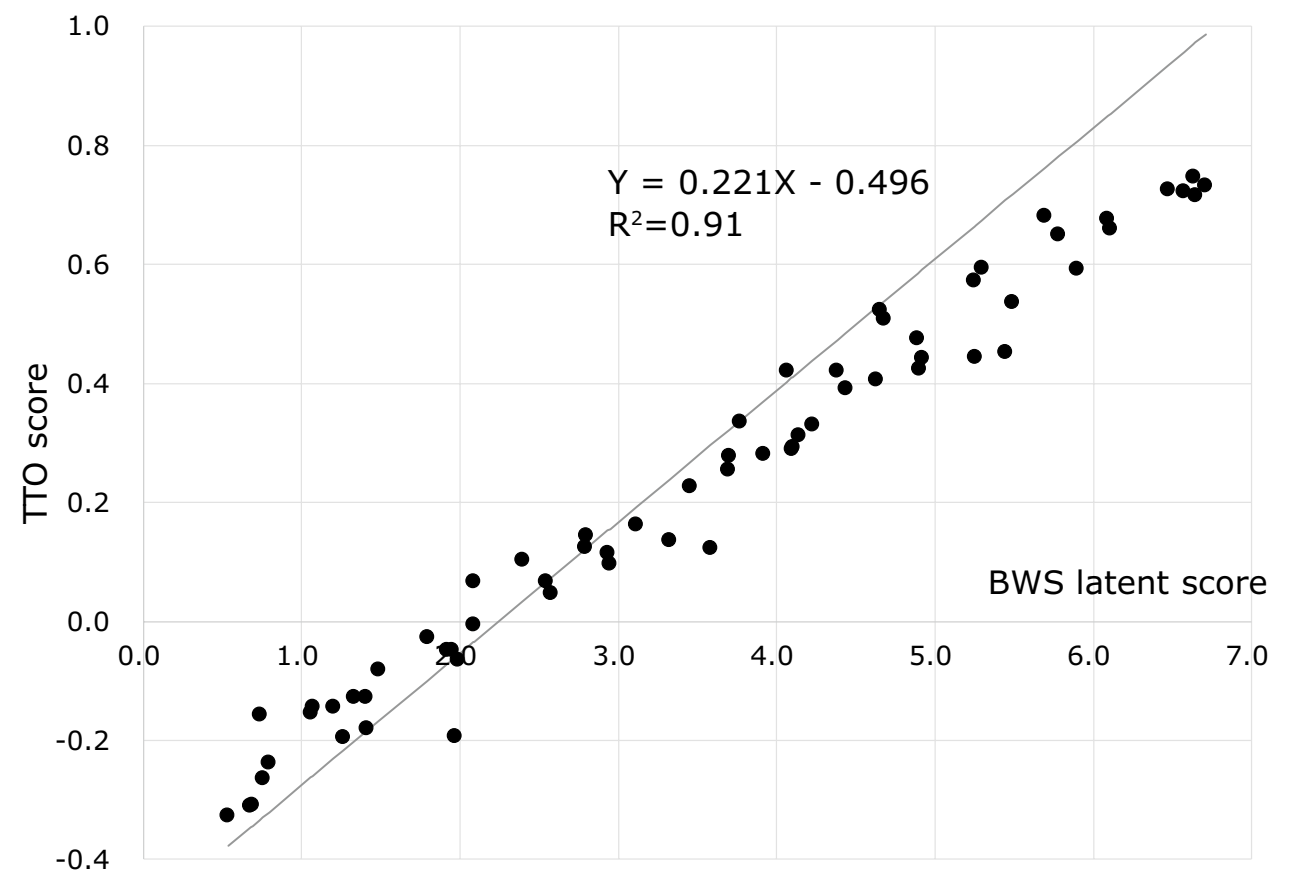

Fig. 3 Comparison between Japanese and UK scores for all ASCOT patterns obtaining QOL scores) is unknown, although in other countries, several studies have been published [37-39]. Moreover, the population norms of SC-QALY scores may help us interpret the obtained data, for example, SC-QALY scores by care level (in Japan, long-term care insurance is provided according to 7 severity categories, with care level 5 being the most severe). A future study is warranted to address these issues. Nevertheless, the present study should serve as a catalyst to promote outcomes research in
Japan, including economic evaluation in the area of social care.

Funding This study was partly funded by JSPS KAKENHI (Grants Numbers JP16K08898 and JP16H03722).

\section{Compliance with ethical standards}

Conflict of interest All authors declare no conflicts of interest. 
Ethical approval All procedures performed were in accordance with the Ethical Guidelines for Clinical Research of the Japanese Ministry of Health, Labour and Welfare and with the 1964 Helsinki declaration and its later amendments.

Informed consent Informed consent was obtained from each individual participant included in the study.

Open Access This article is distributed under the terms of the Creative Commons Attribution 4.0 International License (http://creativeco mmons.org/licenses/by/4.0/), which permits unrestricted use, distribution, and reproduction in any medium, provided you give appropriate credit to the original author(s) and the source, provide a link to the Creative Commons license, and indicate if changes were made.

\section{Appendix: How to calculate SC-QALY}

For example, in the case that a response to ASCOT is "24313222", the SC-QALY score can be calculated as follows:

1. Using Table 3, weights of eight item should be added. For example, the weight of level 2 in the "Control over daily life" domain is 0.954 . Similarly, the weight of level 4 in the "Personal cleanliness and comfort" domain is 0.141 . So, the total weight of " 24313222 " is $0.954+0$. $141+0.247+0.717+0.345+0.975+0.825+0.347=4$ .551

2. Total weight calculated in 1 is converted to utility as the following equation:

SC-QALY score $=(0.221 \times$ totalweight $)-0.496$.

In the case of " 24313222 ", as total weight is 4.551 , SC-QALY can be calculated by $(0.221 \times 4.551)-0.496=0.51$.

\section{References}

1. Ministry of Internal Affairs and Communications. (2016). Population estimates (2016). Chiyoda: Ministry of Internal Affairs and Communications.

2. United Nations. (2016). World population prospects. New York: United Nations.

3. National Institute of Population and Social Security Research. (2017). Population projection for Japan. Tokyo: National Institute of Population and Social Security Research.

4. Mahoney, F. I., \& Barthel, D. W. (1965). Functional evaluation: The barthel index. Maryland State Medical Journal, 14, 61-65.

5. EuroQol Group. (1990). EuroQol-A new facility for the measurement of health-related quality of life. Health Policy, 16(3), 199-208.

6. Herdman, M., Gudex, C., Lloyd, A., Janssen, M., Kind, P., Parkin, D., et al. (2011). Development and preliminary testing of the new five-level version of EQ-5D (EQ-5D-5L). Quality of Life Research, 20(10), 1727-1736. https://doi.org/10.1007/s1113 6-011-9903-x.
7. Feeny, D., Furlong, W., Boyle, M., \& Torrance, G. W. (1995). Multi-attribute health status classification systems. Health Utilities Index. Pharmacoeconomics, 7(6), 490-502.

8. Brazier, J., Usherwood, T., Harper, R., \& Thomas, K. (1998), Deriving a preference-based single index from the UK SF-36 Health Survey. Journal of Clinical Epidemiology, 51(11), 1115-1128.

9. Morikawa, M., Nakamura, H., Moriyama, Y., \& Shiroiwa, T. (2018). Japanese translation of the Adult Social Care Outcomes Toolkit (ASCOT) as social care related quality of life measures: Focus on the linguistic validation. Journal of the National Institute of Public Health, 67(3), 313-321.

10. Netten, A., Burge, P., Malley, J., Potoglou, D., Towers, A. M., Brazier, J., et al. (2012). Outcomes of social care for adults: Developing a preference-weighted measure. Health Technology Assessment, 16(16), 1-166. https://doi.org/10.3310/hta16160.

11. Rand, S., Malley, J., Towers, A. M., Netten, A., \& Forder, J. (2017). Validity and test-retest reliability of the self-completion adult social care outcomes toolkit (ASCOT-SCT4) with adults with long-term physical, sensory and mental health conditions in England. Health and Quality of Life Outcomes, 15(1), 163. https ://doi.org/10.1186/s12955-017-0739-0.

12. Malley, J. N., Towers, A. M., Netten, A. P., Brazier, J. E., Forder, J. E., \& Flynn, T. (2012). An assessment of the construct validity of the ASCOT measure of social care-related quality of life with older people. Health and Quality of Life Outcomes, 10, 21. https ://doi.org/10.1186/1477-7525-10-21.

13. van Leeuwen, K. M., Bosmans, J. E., Jansen, A. P., Rand, S. E., Towers, A. M., Smith, N., et al. (2015). Dutch translation and cross-cultural validation of the Adult Social Care Outcomes Toolkit (ASCOT). Health and Quality of Life Outcomes, 13, 56. https://doi.org/10.1186/s12955-015-0249-x.

14. Torrance, G. W., Boyle, M. H., \& Horwood, S. P. (1982). Application of multi-attribute utility theory to measure social preferences for health states. Operations Research, 30(6), 1043-1069.

15. Xie, F., Pullenayegum, E., Pickard, A. S., Ramos Goni, J. M., Jo, M. W., \& Igarashi, A. (2017). Transforming latent utilities to health utilities: East does not meet west. Health Economics, 26(12), 1524-1533. https://doi.org/10.1002/hec.3444.

16. Smith, N., Towers, A., \& Razik, K. (2017). Adult Social Care Outcomes Toolkit (ASCOT) SCT4 guidance. Version 1. Discussion paper 2937. Canterbury: Personal Social Services Research Unit. University of Kent.

17. Flynn, T. N., Louviere, J. J., Peters, T. J., \& Coast, J. (2007). Best-worst scaling: What it can do for health care research and how to do it. Journal of Health Economics, 26(1), 171-189. https ://doi.org/10.1016/j.jhealeco.2006.04.002.

18. Louviere, J. J., Flynn, T. N., \& Marley, A. A. J. (2015). Bestworst scaling: Theory, methods and applications. Cambridge: Cambridge University Press.

19. Flynn, T. N., Huynh, E., Peters, T. J., Al-Janabi, H., Clemens, S., Moody, A., et al. (2015). Scoring the Icecap-A capability instrument. Estimation of a UK general population tariff. Health Economics, 24(3), 258-269. https://doi.org/10.1002/hec.3014.

20. Rowen, D., Brazier, J., Young, T., Gaugris, S., Craig, B. M., King, M. T., et al. (2011). Deriving a preference-based measure for cancer using the EORTC QLQ-C30. Value Health, 14(5), 721-731. https://doi.org/10.1016/j.jval.2011.01.004.

21. Cheung, K. L., Wijnen, B. F., Hollin, I. L., Janssen, E. M., Bridges, J. F., Evers, S. M., et al. (2016). Using best-worst scaling to investigate preferences in health care. Pharmacoeconomics, 34(12), 1195-1209. https://doi.org/10.1007/s40273-016-0429-5.

22. Potoglou, D., Burge, P., Flynn, T., Netten, A., Malley, J., Forder, J., et al. (2011). Best-worst scaling vs. discrete choice experiments: An empirical comparison using social care data. Social Science 
and Medicine, 72(10), 1717-1727. https://doi.org/10.1016/j.socsc imed.2011.03.027.

23. Torrance, G. W. (1986). Measurement of health state utilities for economic appraisal. Journal of Health Economics, 5(1), 1-30.

24. Dolan, P., Gudex, C., Kind, P., \& Williams, A. (1996). Valuing health states: A comparison of methods. Journal of Health Economics, 15(2), 209-231.

25. Devlin, N. J., Tsuchiya, A., Buckingham, K., \& Tilling, C. (2011). A uniform time trade off method for states better and worse than dead: Feasibility study of the 'lead time' approach. Health Economics, 20(3), 348-361. https://doi.org/10.1002/hec.1596.

26. Devlin, N., Buckingham, K., Shah, K., Tsuchiya, A., Tilling, C., Wilkinson, G., et al. (2013). A comparison of alternative variants of the lead and lag time TTO. Health Economics, 22(5), 517-532. https://doi.org/10.1002/hec.2819.

27. Attema, A. E., Versteegh, M. M., Oppe, M., Brouwer, W. B., \& Stolk, E. A. (2013). Lead time TTO: Leading to better health state valuations? Health Economics, 22(4), 376-392. https://doi. org/10.1002/hec.2804.

28. Train, K. E. (2008). Discrete choice methods with simulation (2nd ed.). Cambridge: Cambridge University Press.

29. Malley, J., \& Louviere, J. (2005). Some probabilistic models of best, worst, and best-worst choices. Journal of Mathematical Psychology, 49, 464-480.

30. Ministry of Health, Labour and Welfare. (2017). Comprehensive survey of living conditions. Tokyo: Ministry of Health, Labour and Welfare.

31. Statistics Bureau, Ministry of Internal Affairs and Communications. (2017). Labour force survey. Tokyo: Statistics Bureau, Ministry of Internal Affairs and Communications.

32. Statistics Bureau, Ministry of Internal Affairs and Communications. (2017). Population estimates. Tokyo: Statistics Bureau, Ministry of Internal Affairs and Communications.
33. Statistics Bureau, Ministry of Internal Affairs and Communications. (2017). Natonal census. Tokyo: Statistics Bureau, Ministry of Internal Affairs and Communications.

34. Shiroiwa, T., Fukuda, T., Ikeda, S., Takura, T., \& Moriwaki, K. (2017). Development of an official guideline for the economic evaluation of drugs/medical devices in Japan. Value Health, 20(3), 372-378. https://doi.org/10.1016/j.jval.2016.08.726.

35. Shiroiwa, T., Ikeda, S., Noto, S., Igarashi, A., Fukuda, T., Saito, S., et al. (2016). Comparison of value set based on DCE and/or TTO data: Scoring for EQ-5D-5L health states in Japan. Value Health, 19(5), 648-654. https://doi.org/10.1016/j.jval.2016.03.1834.

36. Devlin, N. J., Shah, K. K., Feng, Y., Mulhern, B., \& van Hout, B. (2018). Valuing health-related quality of life: An EQ-5D-5L value set for England. Health Economics, 27(1), 7-22. https://doi. org/10.1002/hec. 3564 .

37. van Leeuwen, K. M., Bosmans, J. E., Jansen, A. P., Hoogendijk, E. O., van Tulder, M. W., van der Horst, H. E., et al. (2015). Comparing measurement properties of the EQ-5D-3L, ICECAP-O, and ASCOT in frail older adults. Value Health, 18(1), 35-43. https:// doi.org/10.1016/j.jval.2014.09.006.

38. van Leeuwen, K. M., Jansen, A. P., Muntinga, M. E., Bosmans, J. E., Westerman, M. J., van Tulder, M. W., et al. (2015). Exploration of the content validity and feasibility of the EQ-5D-3L, ICECAP$\mathrm{O}$ and ASCOT in older adults. BMC Health Services Research, 15, 201. https://doi.org/10.1186/s12913-015-0862-8.

39. Stevens, K., Brazier, J., \& Rowen, D. (2018). Estimating an exchange rate between the EQ-5D-3L and ASCOT. The European Journal of Health Economics, 19(5), 653-661. https://doi. org/10.1007/s10198-017-0910-x.

Publisher's Note Springer Nature remains neutral with regard to jurisdictional claims in published maps and institutional affiliations.

\section{Affiliations}

\section{Takeru Shiroiwa $^{1} \mathbb{D} \cdot$ Yoko Moriyama $^{2} \cdot$ Hiromi Nakamura-Thomas ${ }^{3} \cdot$ Mie Morikawa $^{4} \cdot$ Takashi Fukuda $^{1,2}$. Laurie Batchelder ${ }^{5}$. Eirini-Christina Saloniki ${ }^{5}$. Juliette Malley ${ }^{6}$}

1 Center for Outcomes Research and Economic Evaluation for Health (C2H), National Institute of Public Health, 2-3-6 Minami, Wako, Saitama 351-0197, Japan

2 Department of Health and Welfare Services, National Institute of Public Health, 2-3-6 Minami, Wako, Saitama 351-0197, Japan

3 Graduate School of Health, Medicine and Welfare, School of Occupational Therapy, Saitama Prefectural University, 820 Sannomiya, Koshigaya, Saitama 343-8540, Japan
4 Department of Policy Studies, Tsuda University, 1-18-24 Sendagaya, Shibuya-ku, Tokyo 151-0051, Japan

5 Personal Social Services Research Unit (PSSRU), Cornwallis Central, University of Kent, Canterbury, Kent CT2 7NF, UK

6 Personal Social Services Research Unit (PSSRU), London School of Economics and Political Science (LSE), Houghton Street, London WC2A 2AE, UK 